\title{
К ВОПРОСУ О ПЕРЕВОДЕ НАЗВАНИЙ КВЕСТОВ В КОМПЬЮТЕРНЫХ ИГРАХ (НА ПРИМЕРЕ ИГРЫ «DRAGON AGE: INQUISITION»)
}

\author{
On the Translation of Quest Names in Computer Games \\ (on the Example of the Game "Dragon Age: Inquisition")
}

Keywords: translation, computer games, language localisation, fantasy, Dragon Age Contact: Uniwersytet Śląskiw Katowicach; ziel97@tlen.pl

«Квест» (англ. quest) является термином из области компьютерных игр. С его помощью называем задания в мире игры, которые должен выполнять персонаж игрока с целью получить определенную награду. Квесты составляют один из самых важных компонентов компьютерной ролевой игры; на их основе строится весь игровой процесс (так наз. геймплей). Можно их разделить на главные, связанные с основной сюжетной линией игры, завершение которых требуется для ее окончания, и побочные, не оказывающие значительного влияния на ход игры. Каждый квест имеет отдельное название, которое обычно каким-то образом намекает на его суть или содержание; особенно в компьютерных ролевых играх (англ. RPG) замечается такая тенденция. В настоящей статье мы сосредоточимся именно на этого типа названиях квестов и рассмотрим их русские и польские соответствия. Материал для анализа был почерпнут из игры «Dragon Age: Inquisition», являющейся довольно популярным представителем жанра игр RPG.

«Dragon Age: Inquisition» - это компьютерная ролевая игра, разработанная канадской студией BioWare, премьера которой произошла в 2014 году. Она является продолжением двух предыдущих игр серии: «Dragon Age: Origins» и «Dragon Age II». Персонаж, в которого воплощается игрок - это лидер заглавной Инквизиции, т.е. организации, созданной для разрешения споров на земле Тедаса (континента в мире игры), а также преодоления демонических сил, угрожающих человечеству. Игра, аналогично предыдущим частям серии, относится к жанру фэнтези; ее сюжет сильно сфокусирован на мотиве борьбы со злом, а представленный мир полон магии. Геймплей игры построен на основе 
открытого мира: игрок имеет возможность путешествовать по различным землям на территории Тедаса и завершать многие, связанные с ними задания. Учитывая главные и побочные квесты, квесты спутников, задания ставки командования, стол заявок, коллекции (в том числе те, принадлежащие к загружаемому контенту), «Dragon Age: Inquisition» включает в себя почти 800 квестов. Мы проанализируем лишь некоторые примеры, являющиеся, на наш взгляд, особо интересными.

Однако, прежде чем перейти к предмету настоящей статьи, следует уделить некоторое внимание вопросу языковой локализации, чтобы подчеркнуть, какое значение имеет соответствующий перевод в компьютерных играх. Суть локализации игр - сохранить игровой процесс для целевых игроков таким образом, как будто игра оригинально была разработана на их языке, и доставить удовольствие, эквивалентное тому, которое испытывают игроки оригинальной версии (Mangiron, O’Hagan 2006: 14-15). Элементы геймплея, подвергающиеся переводу (такие как интерактивные диалоги персонажей, кат-сцены, т.е. внутриигровое видео, содержание журнала квестов, содержимое инвентаря, древо навыков, а также названия предметов или других элементов, связанных с взаимодействием персонажа с окружающей средой в игровом мире и т.д. $\left.{ }^{1}\right)$ чаще всего выполняют информативную (но не только) функцию. Они позволяют расширить знания игрока об игровом контенте, но и подчеркнуть созданный авторами внутриигровой сеттинг (т.е. уникальную вселенную игры). Стоит здесь упомянуть о явлении иммерсии. Иммерсия представляет собой ощущение погружения в представленный в игре мир. Она составляет довольно важный аспект игрового процесса, поскольку самое главное в приеме игры - это переживание сюжета таким образом, чтобы игрок «слился» со своим персонажем и чувствовал себя участником происходящих на экране событий (Мӓуrä 2008: 108-110). Не подлежит сомнению утверждение, что соответствующая локализация игры способствует также явлению иммерсии, т.е. усиливает потенциальный прием игры.

Осознавая все существенные для нас теоретические моменты, мы перейдем к практической части статьи. Сравним оригинальную английскую версию названий квестов из игры «Dragon Age: Inquisition» с их переводами на русский и польский языки. Данные названия мы классифицировали по их структуре.

\footnotetext{
${ }^{1}$ О специфике перевода разных элементов в компьютерных играх см. больше: Drab 2017: 103-105. 


\section{Группа I}

В первую группу включаются названия, структура которых основывается на предлоге $o f$, передающем значение русского и польского родительного падежа:

The Wrath of Heaven - Небесный гнев; Gniew niebios;

The Loss of a Friend - Погибший друг; Strata przyjaciela;

The Spoils of Desecration - Кошунство и святотатство; Zdobycze profanacji;

Memories of the Grey - B память о Cmражах; Szare wspomnienia.

В случае первых двух примеров, замечается тенденция русского переводчика строить названия на основе прилагательного в качестве определения существительного (Небесный гнев, Погибший друг). В третьем примере произошла модификация: употребляются здесь два синонимических существительных (Кощунство и святотатство). Польский переводчик, в свою очередь, принял решение передать эти названия с помощью несогласованного определения (Gniew niebios, Strata przyjaciela, Zdobycze profanacji). Интересным кажется перевод последнего примера на оба языка. Grey относится к полному названию древнего ордена - Grey Wardens (рус. Cерые Cmражи, польск. Szara Straż). Данный квест состоит в обнаружении артефактов в старых лагерях и форпостах Стражей. Русский переводчик решил здесь уточнить содержащийся намек, употребляя название $B$ память о Стражах. Польский же - вместо аналогичной оригиналу форме несогласованного определения применил присущее членам этого ордена прилагательное szary в качестве определения признанного эквивалента английского memories, т.e. wspomnienia.

The Heart of the Still Ruins - Сердие Безветренных руин; W sercu

Nieruchomych Ruin;

The Corruption of Sahrnia - Заражение Cарнии; Zepsucie w Sahrni;

The Vault of Valammar-Валаммарское хранилище; Skarbiec

$w$ Valammarze.

По всей видимости, и в русской версии отмечаем перевод анализируемой нами структуры с использованием несогласованного определения (Сердие Безветренных руин, Заражение Сарнии), хотя в случае последнего примера снова появляется прилагательное как определение существительного (Валаммарское хранилище). Касательно польского перевода, - учитывая, что все вышеприведенные примеры содержат название какой-то локализации, - добавлен здесь предлог w (W sercu Nieruchomych Ruin, Zepsucie w Sahrni, Skarbiec $w$ Valammarze). 


\section{Группа II}

Одной из составляющих названий второй группы является притяжательная форма существительного:

The Magister's Birthright - Право первородства; Rodowód magistra; My Lover's Phylactery - Амулет любимой; Filakterium mojej kochanki; A Lover's Promise - Обещание влюбленного; Obietnica kochanki; The Knights' Tomb - Рыщарская гробница; Grobowiec rycerza; A Father's Guidance - Отиовские указания; Wskazówki ojca; A Father's Name - Отиовское имя; Nazwisko ojca; Mата's Ring - Мамино кольцо; Pierścień mamy.

Относительно этой структуры замечаем отчетливые тенденции. В польской версии, без исключений, используются несогласованные определения. На русский язык они переводятся либо так же, как на польский (Право первородства, Амулет любимой, Обещание влюбленного), либо с помощью прилагательного (Рыцарская гробница, Отиовские указания, Отцовское имя, Мамино кольио). Кроме того, мы хотим уделить дополнительное внимание трем первым примерам. Во вселенной Dragon Age титул Magister (рус. магистр, польск. magister) относится к магам-членам Сената одной из Империй Тедаса. В русском переводе квеста The Magister's Birthright этот элемент опущен. В польском он присутствует в сочетании с лексемой rodowód, обладающей сходным, но не идентичным значением, что лексема birthright. По поводу названий, компонентом которых является слово lover, следует подчеркнуть, что, в связи с присутствием категории рода в русском и польском языках, пришлось здесь определить, касается ли оно женщины либо мужчины. Сомнения вызывает пример A Lover's Promise, в котором пол различается на языках перевода. Ознакомившись с содержанием квеста (юноша в письме предлагает любимой встретиться, чтобы сбежать вместе), становится ясным, что в этом случае русский вариант оказался правильным.

\section{Группа III}

К третьей группе принадлежат названия, компонентом которых выступает имя прилагательное в качестве определения существительного:

A Dalish Perspective - Взгляд долийщев; Dalijski punkt widzenia;

Tough Love - Любовь по-кунарийски; Madra mitość;

Rocky Rescue - Спасение среди камней; Ratunek wśród skat;

Avvar Allies - Aввары-союзники; Awarscy sojusznicy;

Strange Bedfellows - Необычный дуэт; Niecodzienni towarzysze;

Guily Pleasures - Тайное увлечение; Wstydliwa lektura. 
Как видим, в русской версии названия, построенные аналогично оригиналу на основе прилагательное + существительное, появляются лишь в двух выбранных нами примерах (Необычный дуэт, Тайное увлечение). Остальные переведены описательно (Взгляд долийцев, Спасение среди камней) или как сложные существительные (Аввары-союзники). В польской версии замечаем тенденцию переводить аналогично подлиннику, т.е. с помощью прилагательного и существительного, но появился и описательный перевод (Ratunek wśród skat). Стоит обратить внимание на модификацию названия квеста Tough Love, связанного с романом со спутником - представителем расы Кунари. Русский переводчик уточнил здесь содержание задания (Любовь по-кунарийски), польский - использовал другое, чем в оригинале прилагательное (Madra miłość). Интересным является также польский перевод последнего примера. Данный квест касается одной из спутниц, которая втайне читает любовные романы. Польский признанный эквивалент фразы guilty pleasure - это «grzeszna przyjemność». Однако, слово grzeszny могло бы вызывать здесь нежелательные религиозные коннотации и, вероятно, поэтому переводчик решил отнестись к элементу сюжета.

A Superior Tower - Bсе выше, выще и выше; Lepsza wież;

A Greener Garden - Oü, в моем садочке; Zieleńszy ogród.

Вышеприведенные квесты касаются улучшения крепости главного героя и именно поэтому в их названиях появились прилагательные в сравнительной степени. На польский язык они были переведены буквально. Русский переводчик проявил более творческий подход к этому вопросу.

Noble Deeds, Noble Heart - Благородство в сердие и делах;

Szlachetne czyny i serce;

Wicked Eyes and Wicked Hearts - Злье глаза и злье сердиа; Oczy i serca przebiegte;

Another Side, Another Story - Другая история; Inna strona, inna historia.

Данные названия построены на основе повторения прилагательного по отношению к разным существительным. В переводах эта особая структура отображена лишь в случае двух примеров: Злье глаза и злье сердияа и Inna strona, inna historia. Остальные переводы опираются либо на опущение повторяемого элемента (Szlachetne czyny i serce, Oczy i serca przebiegłe) или фрагмента названия (Другая история), либо строятся совсем по-другому (Благородство в сердие и делах). 


\section{Группа IV}

В четвертую группу входят названия, содержащие в оригинале сказуемое:

Here Lies the Abbys - Там лежит Бездна; Oto jest otchtan';

The Threat Remains - Опасность не миновала; Nieustajace zagrożenie;

This Water Tastes Funny - Забавный вкус у этой воды; Ta woda dziwnie smakuje;

These Demons Are Clever - Xитрые демоны; Sprytne sa te demony;

It Remains to be Seen - Время покажет; Dostrzec niewidoczne;

They Came From Somewhere Else - Все было не так; Przybyli skadinad;

They Shall Not Pass - Bpaz не nройdem!; Ani kroku dalej;

Not Everyone's Free - Невольники вольных; Nie każdy jest wolny.

Сравнивая переводы, легко отметить, что в большинстве случаев также присутствует сказуемое. Некоторые из них переведены довольно буквальным образом, иногда с небольшими модификациями (Там лежит Бездна, Забавный вкус у этой водыр; Oto jest otchtań, Ta woda dziwnie smakuje, Sprytne sa te demony, Przybyli skadinad, Nie każdy jest wolny). В русской версии встречается и пример антонимического перевода (Опасность не миновала). Остальные названия отличаются на уровне формы, но они все равно передают смысл подлинника, относясь к содержанию квеста (Время покажет, Все было не так, Враг не nройdem!; Dostrzec niewidoczne). Исключениями от анализируемых нами названий, содержащих сказуемое, являются примеры перевода с помощью структур, которые мы рассматривали в предыдущей части этой статьи (Nieustajace zagrożenie; Хитрые демоны; Невольники вольных).

Bring Me the Heart of Snow White - Сердие снежного виверна;

Przynieś mi serce Śnieżki;

Sit in Judgement - Cyd udem; Weź udział w rozprawie;

Know Thy Enemy - Знай врага своего; Znaj swego wroga.

Есть и названия, содержащие глаголы в повелительном наклонении. Они переводятся на польский язык буквально (Przynieś mi serce Śnieżki; Znaj swego wroga) или описательно (Weź udziat w rozprawie). В русской версии лишь один пример построен аналогичным оригиналу образом (Знай врага своего). Стоит отметить, что в русском переводе названия Bring Me the Heart of Snow White имя Snow White (рус. Белоснежка, польск. Śnieżka) заменено определением вида ящероподобного животного, приобретение сердца которого является целью этого квеста. Достойным внимания является также вопрос устаревшего наполнения местоимения thy в названии квеста Know Thy Enemy, которое русский переводчик отобразил на уровне синтаксиса (Знай врага своего). Польский, в свою очередь, применил местоимение swego, характерное для высокого, литературного стиля. 
Seeing Red - В красных тонах; Wszystko na czerwono;

Weeding Out Bandits - Долой сорняки; Wyrywanie chwastów;

Throwing Away Money - Деньги в воду; Utopione pieniadze;

Passing Notes - Передача записей; Pożegnalne notatki.

К этой группе принадлежат также названия, компонентом которых является глагол в неличной форме, так наз. герундий. Вопрос их перевода кажется нам интересным прежде всего вследствие того, что как в русском, так и польском языках эквивалента герундию не существует. Как могло бы показаться, самой близкой ему формой является отглагольное существительное, но в переводе оно появляется лишь в одном примере (Wyrywanie chwastów). Итак, в первом названии переводчики решили подчеркнуть красный цвет, который является ключевым элементом в данном задании. Во втором - отмечаем опущенный элемент bandits. Внимание обращается на глагол weeding out, а упомянутые бандиты считаются сорняками. Суть квеста Throwing Away Money заключается в том, чтобы бросать специальные монетки в фонтан; в обоих переводах находим ссылку именно на это действие. Что касается последнего названия, наблюдаем здесь разные подходы переводчиков. Слово passing можно воспринимать либо как отглагольное существительное от передавать, либо как прилагательное, связанное с умиранием. Итак, здесь каждый переводчик выбрал другой вариант. Тем не менее, зная содержание данного квеста, оба названия подходят.

\section{Группа V}

В последнюю группу мы включили названия, содержащие предлог. Он находится либо в их начале, либо посередине. Начнем с первых:

In Hushed Whispers - По секрету; Szeptem;

In the Elements - Во власти стихий; Wśród żywiołów;

By the Grace of the Dalish - Долийское снисхождение; Z łaski

Dalijczyków;

Under Her Skin - Пристальное внимание; Zaleźć jej za skórę;

Of Somewhat Fallen Fortune - Злой рок; Los spotkat ich smutny.

Снова проявляется здесь тенденция русского переводчика передавать названия с помощью существительного и определяющего его прилагательного (Долийское снисхождение, Пристальное внимание, Злой рок). На примере двух последних названий можно заметить, что перевод не относится к оригиналу, но содержит ссылку на содержание квеста. Что касается остальных примеров, они также переведены с использованием предлогов, передавая основной смысл (По секрету, Во власти стихий). В польской версии буквально переведено одно из 
приведенных названий (Z łaski Dalijczyków). Остальные из них переданы недословным образом. Из-за языковых различий они приняли форму наречия (Szeptem), содержат другой предлог (Wśród żywiołów), инфинитив (Zaleźć jej za skórę) либо глагол в личной форме (Los spotkat ich smutny). Хотим подчеркнуть особый перевод последнего примера. Касающийся его квест связан с неблагоприятным положением семьи одной из советниц главного героя. Итак, в очередной раз переводчики полностью изменили название задания, опираясь на знания о его содержании.

Someone to Lose - Ecmь кого терять; Bliska osoba;

Something to Prove - Показать и доказать; Coś do udowodnienia;

A Bear to Cross - Размедвеживание; Uwaga na niedźwiedzia;

Beasts at Bay - Защиuma om зверей; Odstraszanie dzikich zwierząt;

Doom Upon All the World - Дивитесь же совершенству; Zagłada na cały świat.

Учитывая также предыдущие примеры, следует признать, что названия из этой группы являются наиболее разнообразными с точки зрения перевода. Видно здесь, что переводчики руководствовались нуждой передать смысл подлинника максимально адекватно, но также воспользовались знаниями о содержании квестов. В русской версии замечаем здесь глагольные формы (Ecmь кого терять, Показать и доказать, Дивитесь же совершенству), появляется также шутливый неологизм (Размедвеживание). Название Beasts at Bay на обоих языках передает информацию о потенциальной охоте на зверей. Однако, наше удивление вызывает русский вариант последнего примера (финального квеста игры), который кажется не иметь отношения к исходному названию и не намекать на содержание задания. Что касается польской версии, то замечаем два буквальных перевода (Cośdo udowodnienia, Zagłada na cały świat); остальные названия позволяют игроку догадаться, с чем связан данный квест.

Наконец, уже вне нашей категоризации, хотим обратить внимание на пример, который мы решили рассмотреть отдельно: All New, Faded for Her. Этот квест одного из спутников имеет довольно загадочное название. Как оказывается, это анаграмма от «Dread Wolf, Fen'Harel», образующая скрытую личность нашего компаньона. Переводчики не отразили этой детали в переводе, лишь отнеслись к содержанию задания. Русское соответствие это Вне родной стихии, польское Piękna, nowa Pustka (причем Pustka является неким местом в мире игры). 


\section{Итоги}

Подводя итоги, можно заметить определенные тенденции переводчиков относительно конкретных структур названий квестов. Однако, от них бывают многие исключения, поэтому здесь нет возможности четко назвать правила, которыми руководствовались переводчики в ходе перевода. Стоит подчеркнуть, что они часто пользовались знаниями о содержании того или иного квеста, которые иногда влияли на их окончательное решение. Тем не менее, следует признать, что большинство проанализированных нами названий передает смысл и информацию, содержащиеся в оригинале и хорошо вписывается в сеттинг внутриигрового мира.

\section{Summary}

The above article oscillates around the topic of translating quest names in computer games. The issue has been presented on the basis of the exemplification material taken from the computer role-playing game "Dragon Age: Inquisition". The analysis shows the Russian and Polish translators' different tendencies regarding variously constructed names of in-game missions.

\section{Литература}

Domaciuk-Czarny, I. Uwagi o nazwach własnych w tekstach gier komputerowych z gatunku fantasy. Prace Językoznawcze. 2016 (18/3), c. 19-29.

Drab, E. Gry wideo a przekład: nowe pole badań w obrębie tłumaczenia audiowizualnego. Rocznik Przekładoznawczy. 2017 (9), c. 101-114.

Inglot, K. Nazwy własne a lokalizacja gier elektronicznych fantasy - o potrzebie przekładu oraz wybranych tendencjach w tłumaczeniu gier anglojęzycznych na rynek polski i niemiecki. Homo Ludens. 2013 (5/1), c. 73-81.

Mangiron, C., O’Hagan, M. Game Localisation: Unleashing Imagination with 'Restricted' Translation. The Journal of Specialised Translation. 2006 (6), c. $10-21$.

Mäyrä, F. An Introduction to Game Studies. London: SAGE Publications, 2008. 